\title{
Obama's budget boosts biomedicine
}

Despite an overall freeze on nonmilitary discretionary spending, the US White House's 2011 budget proposal outlays billions of new dollars for biomedical research. The National Institutes of Health $(\mathrm{NIH})$ is the big winner, with a $3.2 \%$ raise amounting to a $\$ 1$ billion bonus - the largest proposed increase for the agency in eight years. The NIH's $\$ 32.2$ billion budget, which would dwarf those of many other organizations, promises to spur research into a number of key areas including cancer, autism and HIV/AIDS. Here we show what's slated to get a shot in the arm should Congress approve the President's proposals.

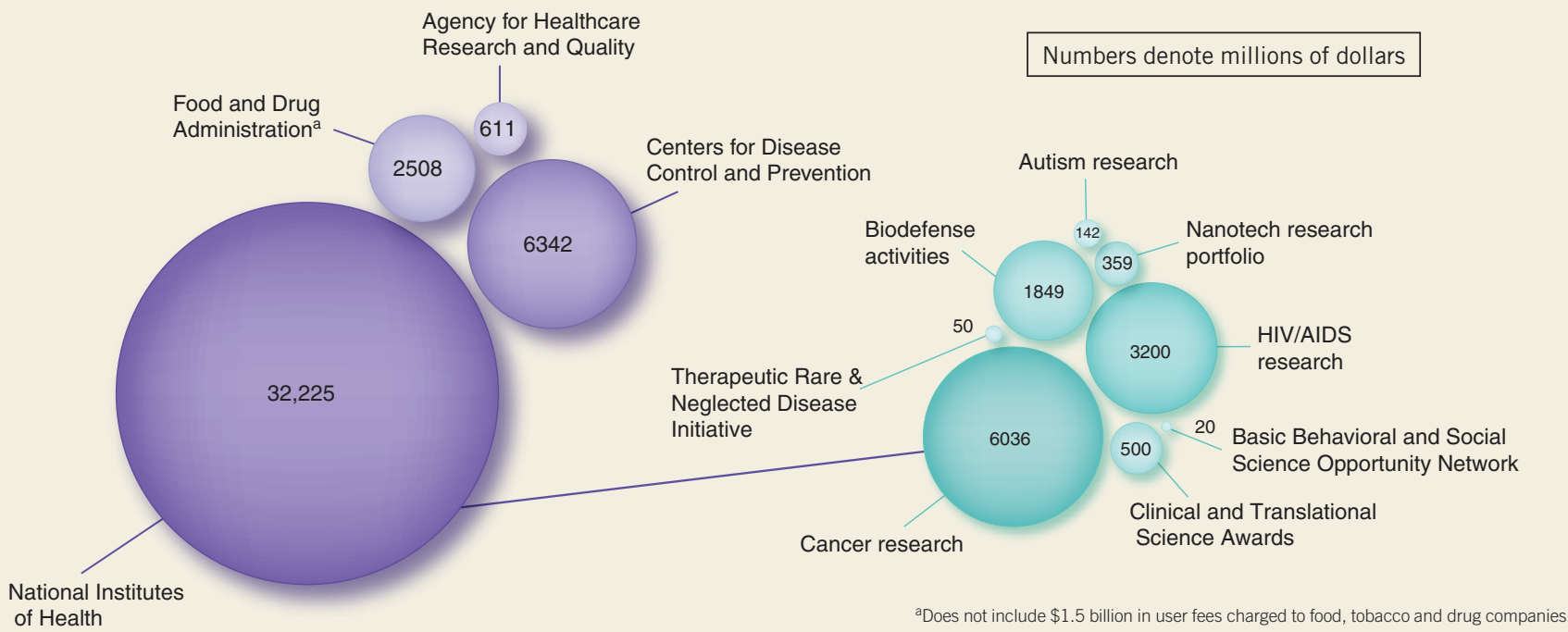

\section{Vaccine funds will save lives}

In a move lauded by global health agencies, Bill and Melinda Gates announced that their foundation would donate $\$ 10$ billion dollars over the next decade to fund vaccine research, development and delivery. This is the Gates Foundation's largest commitment to any global health cause and is more than double the $\$ 4.5$ billion it spent on vaccines last decade.

"[Vaccines are] the most cost-effective way to reach people and to save lives," said Melinda Gates on 29 January at a press conference at the World Economic Forum in Switzerland. According to a model developed by researchers at Johns Hopkins University in Baltimore, the donation could save 8.7 million lives in the coming decade, assuming that the candidate malaria vaccine RTS,S is approved and distributed to at least a million children by 2014 and that $90 \%$ of children are immunized against measles, diphtheria, whooping cough, polio, rotavirus and pneumococcal pneumonia.

At the press conference, the foundation highlighted several priorities, including polio eradication and development of new vaccines for malaria, HIV and tuberculosis.

Cassandra Willyard, New York

\section{Pharma spends big to buy influence}

Despite the slumping economy, the US pharmaceutical and health products industry spent a whopping $\$ 267$ million in 2009 on lobbying efforts-more in one year than any other single industry ever. Steven Findlay, a health policy analyst for Consumers Union in Washington, DC, says that most of this extra expenditure-12\% more than the previous year-stemmed from the beleaguered health care reform bill. "All of these companies stood to gain or lose billions of dollars," he says. "That lobbying started early, and it was intense." Here's a list of all the organizations, including their subsidiaries, that dished out more than $\$ 5$ million in 2009, according to data from the Senate Office of Public Records, to gain access to Washington's power centers and halls of influence.

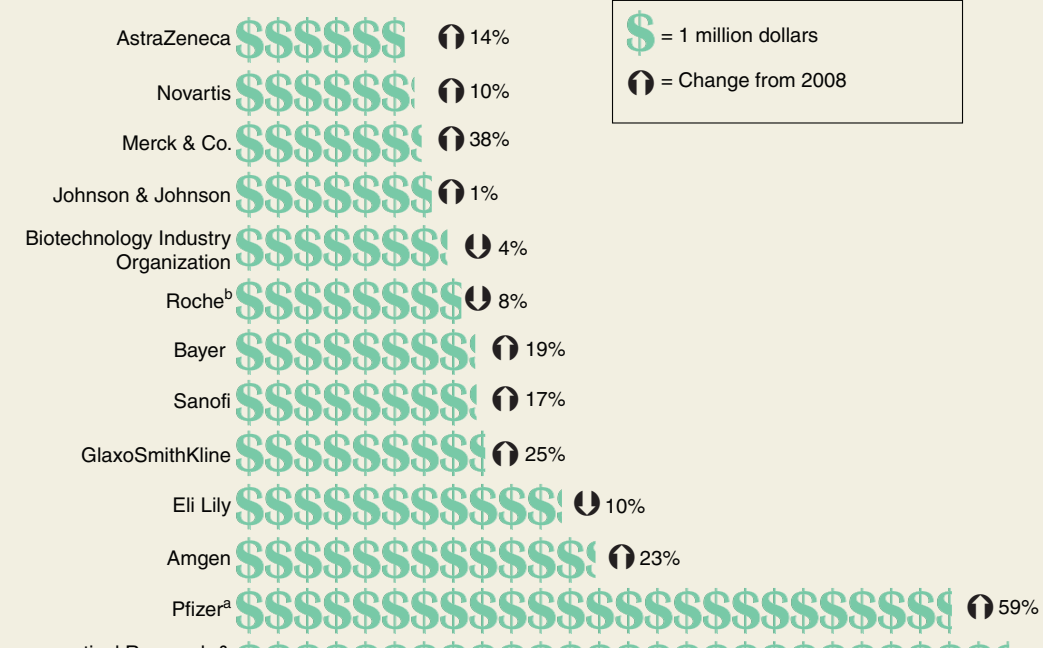

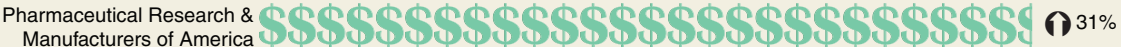

